\title{
A BRIEF SURVEY OF THE ACTIVITIES CONNECTED WITH BIOTECHNOLOGY IN THE UNIVERSITY SYSTEM OF SRI LANKA
}

\section{BALASOORIYA \\ University Grants Commission, Ward Place, Colombo 07.}

My task this morning is to give an overview of the developments that have taken place and are being planned in the university system in the area of biotechnology or in supporting areas. Being away from the laboratory bench for a period of nearly 10 years or more I am compelled to look at this subject from a planning perspective rather than from the perspective of an active research scientist.

It is generally accepted that many of the future developments in the fields of agriculture, industry, medicine, nutrition, environmental and natural resources management will depend to a large extent on advances made in the field of biotechnology. The importance of the new technology was realized all over the world within the last decade or two and already governments and private sector agencies in many countries have given high priority for research and development in genetic manipulation of organisms for increased production of food supplements, fermented products, pharmaceuticals, vaccines etc., management of environmental pollution, and production of new varieties of plants.

There is general agreement among the scientists of this country that development of Biotechnology in Sri Lanka should receive immediate and special consideration because like in most developing countries our economy is based mainly on production of primary commodities from agriculture and natural resources and we are not endowed with reservoirs of fossil fuel.

Although biotechnology has been at the fore-front of scientific endeavour during the last decade or two Sri Lanka has failed to make much headway in this field of study. Lack of trained personnel in the different areas of biotechnology as well as the lack of sophisticated laboratory facilities have greatly retarded advancement in this area of activity in Sri Lanka.

Biotechnology is a multi-disciplinary subject. I believe it is correct to say that Biotechnology stands on three legs - Biochemistry, Microbiology and Genetics. Due to some reason or the other all these three fields of study continued to be somewhat neglected areas in our university system, especially in the Science Faculties, for a long time. This may be one of the contributory factors for the slow development of Biotechnology in the country. In fact one of the strategies adopted by the university system for developing Biotechnology is the attempt to strengthen the training in these three areas at under-graduate level.

The first attempt to introduce Biochemistry as a separate subject into the curriculum of the science faculty took place in the University of Colombo during the 1970's. However this was discontinued after a few years as it was considered a soft 
option compared to Chemistry. After another few years the University of Kelaniya submitted a proposal to the University Grants Commission for starting a Department of Biochemistry in the Faculty of Science. This proposal too could not be implemented due to various difficulties. However, the biochemistry component in the Chemistry, Botany and Zoology curricula in all universities began to progressively increase during the last decade. It is a great pity that we do not yet have a single Department of Biochemistry attached to a science faculty in the university system. Biochemistry units attached to the Department of Chemistry have come into existence at least in two science faculties viz Kelaniya and Colombo during the last few years and these units are likely to develop into full fledged departments within the next few years.

In the meantime all the medical faculties in the country except the new faculty at Sri Jayewardenepura presently have full fledged Departments of Biochemistry. Two of these viz. the departments at Colombo and Jaffna have been conducting M.Sc courses in Biochemistry for the last few years.

Like Biochemistry, Microbiology also continued to be a subject confined to the medical faculties until very recently. Although every medical faculty had a separate Department of Microbiology it was only in the early part of the last decade that the first Department of Microbiology in a science faculty at the University of Kelaniya came into existence. It should be noted however, that the Faculty of Science, University of Peradeniya instituted a Chair in Microbiology in the Department of Botany in the 70's.

None of the universities in the country have a Department of Genetics attached to any of their faculties, although Genetics is being taught in the Faculties of Agriculture, Science and to some extent in Medicine. Again like Biochemistry, the development of the subject of Genetics in the country has been extremely slow due to some inexplicable reason. Certain aspects of Biotechnology pertaining to agriculture feature prominently in the undergraduate curricula of the agriculture faculties and also in the curriculum of the Post-Graduate Institute of Agriculture.

Many universities are making an attempt to strengthen the teaching of Biochemistry, Microbiology and Genetics. The University of Jaffna has already commenced a special degree programme in Biotechnology in the Department of Botany. In addition they conduct an M.Sc Course in Biotechnology.

Research in various aspects of Biotechnology is being carried out in almost all universities. Many of these research programmes centre around single individuals and are being sustained mainly through their personal commitment being financed largely by personal grants. The cost of biotechnology research is such that it will be extremely difficult for a single university to establish and sustain an up-to-date laboratory facility for all areas of biotechnology. A cooperative effort by all the universities in the country for setting up a central facility or better still the setting up of a series of complementary laboratory facilities which could be shared when necessary by others might be one of the ways in which we could address this problem. 